\title{
Patient-reported outcome assessment of
} inflammatory arthritis patient experience with
intravenously administered biologic therapy

This article was published in the following Dove Press journal:

Patient Preference and Adherence

12 September 2017

Number of times this article has been viewed

\author{
Norman B Gaylis' \\ Joanne Sagliani' \\ Shawn Black ${ }^{2}$ \\ Kezhen L Tang ${ }^{3}$ \\ Raphael DeHoratius ${ }^{2,4}$ \\ Wesley A Kafka ${ }^{2}$ \\ Dennis Parenti
}

'Arthritis \& Rheumatic Disease Specialties, Aventura, FL, USA;

${ }^{2}$ Medical Affairs Rheumatology, Janssen Scientific Affairs, LLC, Horsham, PA,

USA; ${ }^{3}$ Quantitative Sciences, Janssen

Research \& Development, LLC, Spring

House, PA, USA; ${ }^{4}$ Department of

Medicine and Pharmacology, Sidney

Kimmel Medical College at Thomas Jefferson University, Philadelphia, PA, USA
Correspondence: Norman B Gaylis Arthritis \& Rheumatic Disease Specialties, 21097 NE 27th Court, Suite 200,

Aventura, FL 33180, USA

Tel +l 3056526676

Email ngaylis@aol.com
Objective: To evaluate patient perspectives regarding utilization of intravenous (IV) therapy for inflammatory arthritis (IA).

Methods: This was a single-center, noninterventional, patient questionnaire-based study of adult IA patients currently receiving IV biologics. At a single visit, patients completed the questionnaire comprising 30 questions centered on their experience receiving an intravenously administered therapy to treat their IA. The questionnaire included questions on patient demographics, disease characteristics, and previous biologic treatment for IA (subcutaneous [SC] and IV). Patients rated their level of agreement with statements regarding satisfaction with current IV biologic therapy and potential advantages and disadvantages of IV biologic therapy using a 5-point Likert scale (1= strongly disagree, 5= strongly agree).

Results: One hundred patients were enrolled and completed the survey; $66 \%$ were female and the mean age was 58 years. Before IV treatment, $97 \%$ of patients received information regarding therapy options. Ninety patients ranked their satisfaction with current IV therapy as 4 or 5 . The proportion of patients with an "extremely favorable" perception of IV therapy increased from $33 \%$ to $71 \%$ following initiation of their current medication. Thirty-one patients had previously received SC therapies to treat their IA.

Conclusion: These results demonstrated an overall favorable perception of IV therapy among this patient population. Patients previously treated with SC therapy also had a positive shift in the perception of IV therapy after initiating IV therapy. Patients' perception and preference for treatment options should be highly considered by the treating physician during or as part of a shared decision-making process.

Keywords: intravenous, patient satisfaction, arthritis, biologic therapy

\section{Introduction}

Currently, biologic agents for treating inflammatory arthritis (IA) are administered either as subcutaneous (SC) injections or intravenous (IV) infusions. Given the variety of biologic therapies available for patients with IA, patient preferences regarding the mode of administration may play an important role in treatment adherence. ${ }^{1}$ Factors that may influence patient preferences for SC or IV treatment include how the drug is administered (ie, self-administered at home vs traveling to a health-care setting), medication storage requirements, and frequency of dosing. Among patients receiving either SC or IV antitumor necrosis factor (TNF) therapy, individual patient preference was reported as fundamental to the selection of a therapeutic agent and route of administration, both of which increased treatment success. ${ }^{2}$ In another survey study, patients with rheumatoid arthritis who were considering anti-TNF therapy 
were equally receptive to both SC and IV agents. ${ }^{3}$ Results derived from a treatment satisfaction questionnaire (TSQM version II) indicated a high level of patient satisfaction with either SC or IV administration. ${ }^{2}$ Progressive data indicate that a shared decision-making process is important to the successful outcomes of a new treatment plan. ${ }^{4,5}$ Thus, it is reasonable that patient preferences for an SC or IV biologic be explored to assess what is optimal for both the patient's and the rheumatologist's treatment goals.

Few studies have addressed the positive or negative attributes associated with specific modes of administration of biologic therapies for inflammatory arthropathies. To address these issues, we developed a questionnaire to explore patient perspectives regarding treatment with an IV biologic. The primary objective was to obtain patientreported outcome (PRO) information that may be used to better understand the treatment perceptions of patients receiving IV biologics for IA.

\section{Methods}

\section{Study design and patients}

The PRO IV study was a single-center, noninterventional, patient questionnaire-based study conducted over $\sim 8$ weeks and enrolled adults with IA who were currently receiving therapy with IV biologics. The protocol was approved by the institutional review board for the site (Western Institutional Review Board). Each patient completed one questionnaire at a single infusion visit. There were no restrictions with respect to the IV biologic used to treat patients' IA.

Adults with a diagnosis of IA were eligible if they were receiving IV biologic treatment for $\geq 3$ months before screening, had the ability to understand and sign an informed consent form, were willing to complete a paper questionnaire, and could read, write, and speak English. Patients were excluded if they had a serious concomitant illness that could otherwise interfere with their ability to complete the questionnaire or if they were participating in any interventional investigational clinical study. Patients were selected from one site and informed that the study would not affect treatment. Written informed consent was obtained from all patients at a screening visit which occurred within 2 weeks before the visit when the questionnaire was administered.

\section{Questionnaire}

The PRO IV questionnaire comprised 30 questions developed to characterize and quantify the patients' experience of receiving an IV therapy to treat their IA. The questionnaire included questions on patient demographics, disease characteristics for which they were receiving their current IV biologic therapy, medical history, previous biologic treatment for IA (including both self-administered SC and IV administrations), education level, insurance status, and whether patients discussed IV therapy with health-care professionals before receiving an IV therapy.

Patients were asked to rate their perception of IV biologic treatment as recalled from before and after receiving treatment with IV therapy using a 5-point Likert scale ( $1=$ not favorable, $5=$ extremely favorable). All patients were asked to rate their agreement with statements regarding satisfaction with their current IV biologic therapy and potential advantages and disadvantages of IV biologic therapy using a 5-point Likert scale ( $1=$ strongly disagree, $2=$ disagree, $3=$ neutral, $4=$ agree, and $5=$ strongly agree). Patients who had previously received an SC biologic therapy for their IA were asked additional questions assessing the potential reasons why they switched from SC to IV administration. This subgroup of patients was presented with several possible reasons for why they switched from an SC to an IV biologic for their IA, and they were asked to rate their agreement with the statements using the 5 -point Likert scale $(1=$ strongly disagree, $5=$ strongly agree).

The questionnaire was administered at the study visit by the study site coordinator. In all cases, the study visit was a regularly scheduled infusion visit, and the questionnaire was completed by the patient in a separate room before the infusion.

\section{Safety}

This was an observational study that did not involve the administration of any therapies to patients. There was no proactive safety data collection component; incidental, spontaneous reports of adverse events or serious adverse events that were described by the patient, either in the patient questionnaire or verbally to members of the clinical study staff during the study, were to be reported. However, no adverse events or other safety data were reported.

\section{Statistical analysis}

Version 3.2.1 of $\mathrm{R}$ and Statistical Analysis System version 9.2 were used for all analyses. Descriptive statistics summarized the questionnaire responses, means and SDs for continuous variables and frequencies and percentages for categorical variables. Bar charts were plotted for categorical variables (eg, favorability ratings before and after IV treatment). Subgroup analyses were performed with patients stratified by previous use of self-administered SC treatment 
(yes/no) to assess patient opinion on IV treatment before and after receiving IV therapy and perceived advantages and disadvantages of SC and IV treatments. McNemar's test was used to evaluate the changes in perception of IV therapy before and after receiving treatment.

\section{Results}

\section{Patient demographics and disease characteristics}

One hundred patients were enrolled, with a mean age of 58.35 years. Mean disease duration was 10.10 years; $68 \%$ had rheumatoid arthritis, 21\% had psoriatic arthritis, 9\% had ankylosing spondylitis, and 2\% had Crohn's disease/IA. Patients were, on average, obese based on a mean body mass index (BMI) of 30.29. The study population was ethnically diverse. The most common comorbidity was hypertension (44\%). A total of $46 \%$ of patients reported graduating college or attending graduate school, and $43 \%$ graduated high school or attended some college. Nearly half of all patients were working full time (48\%), with the next largest group being retired or unemployed (43\%). All but one patient (99\%) reported having health insurance (Medicare, Medicaid, or Private), while $82 \%$ of patients also said they had a prescription plan (Table S1).

The majority of patients reported positive responses to the lifestyle questions: $64 \%$ used daily vitamins, 57\% used additional supplements on a regular basis, $79 \%$ ate a balanced diet (including several servings of fruits and vegetables daily), $85 \%$ tried to get $\geq 7$ hours of sleep each night, and $61 \%$ had a busy/active lifestyle. Among all patients, $45 \%$ reported exercising regularly ( $\geq 3$ times/week). A total of $69 \%$ of patients rated their health as 4 or 5 (1= very poor health, $5=$ perfect health) during the previous month, and $7 \%$ reported a health status of 1 or 2 (Table S1); the mean \pm SD health rating score was $3.86 \pm 0.93$.

\section{Current and previous biologic therapies for inflammatory arthritis}

Among biologics that patients had previously used for their IA, the most commonly used class was anti-TNF agents (infliximab, 20\%; etanercept, 22\%; adalimumab, 19\%; golimumab SC, 3\%; golimumab IV, 1\%). Patients also reported previous treatment with abatacept $(8 \%)$, tocilizumab (4\%), rituximab (2\%), and certolizumab (1\%). A total of $31 \%$ of patients had received SC biologic treatment before starting an IV biologic.

Five IV biologics were reported as current therapies for IA in this population: infliximab (71\%), rituximab (12\%), tocilizumab (10\%), abatacept (6\%), and golimumab (1\%); mean exposures for these therapies were 4.74, 2.94, 1.43, 3.44 , and $0.42(\mathrm{n}=1)$ years, respectively. The overall mean duration of IV therapy was 4.07 years (range: $0.08-16.00$ years). Nearly all patients $(97 \%)$ reported receiving counseling about their IV infusion therapy before initiating treatment; of these, 97\% reported counseling from a physician (part of a shared decision-making experience), 37\% from a nurse or a nurse practitioner, $92 \%$ reported that they had received pamphlets or other reading material in preparation for beginning their IV infusion therapy, and $12 \%$ reported that they were directed to a website for information.

\section{Perceptions of current intravenous biologic therapy for inflammatory arthritis}

Seventy-seven percent of patients were very satisfied (level 5) with using an IV infusion medication (Figure 1A), and one patient $(1 \%)$ indicated a rating of "not at all satisfied" (level 1). The overall mean $\pm \mathrm{SD}$ level of satisfaction with all currently used IV infusion therapies was $4.63 \pm 0.79$. On an individual therapy basis, mean scores were $4.76 \pm 0.60$ for infliximab, $4.67 \pm 0.52$ for abatacept, $4.00 \pm 1.41$ for tocilizumab, $4.33 \pm 0.98$ for rituximab, and $5.0(\mathrm{n}=1)$ for golimumab.

Patients were asked to rate their level of agreement ( $1=$ strongly disagree, $5=$ strongly agree $)$ with statements related to receiving IV therapy for IA. Patients had the highest mean scores for the statements "My doctor felt strongly that an IV medication was the best choice for me," "The doctor can adjust the dose of medication if needed," and "I believe that IV medications are strong medications" (Table 1). Thirty-one patients had previous experience with self-administration of SC biologics. In general, there were no apparent differences between patients with previous SC biologic experience and those without previous SC biologic experience in the relative rank of agreement with these statements (Table 1). However, when compared with patients without prior SC injection experience, patients with prior $\mathrm{SC}$ injection experience had a lower mean agreement score in response to the statement "I would be concerned about the risk of hurting or injuring myself if I had to give myself shots" (4.20 vs 2.77, respectively). A similar trend was observed in response to the statement "I don't like needles and don't like the idea of having to give myself shots" (3.99 vs 3.13, respectively) (Table 1 ).

Patients were queried in regard to their perception of IV therapy to treat their IA before and after starting IV therapy. 

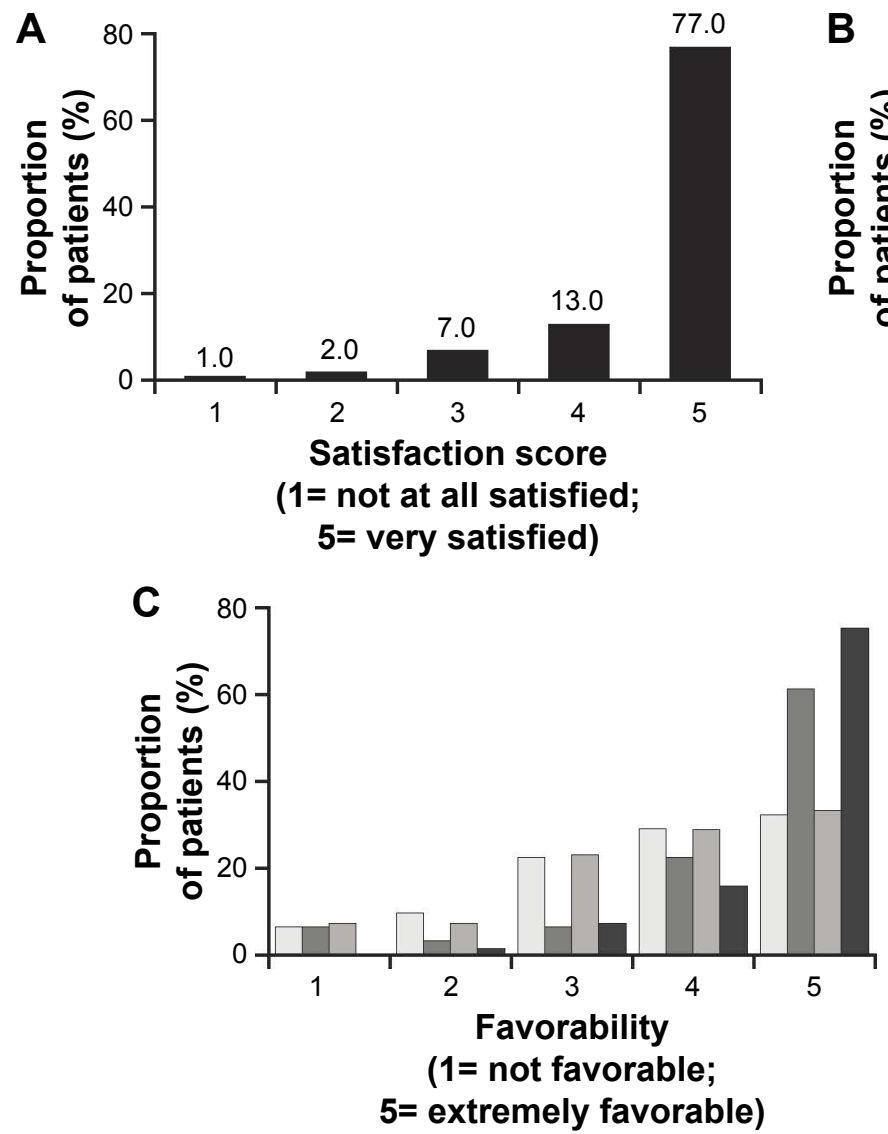

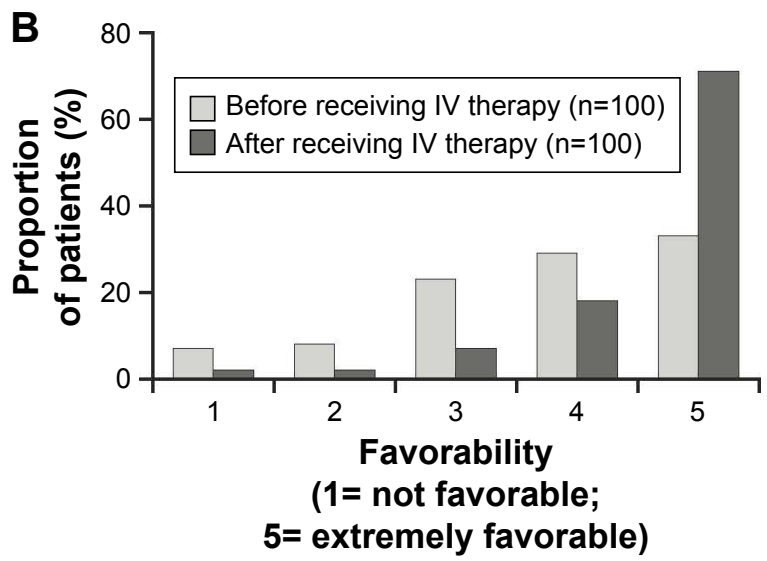

$5=$ extremely favorable)

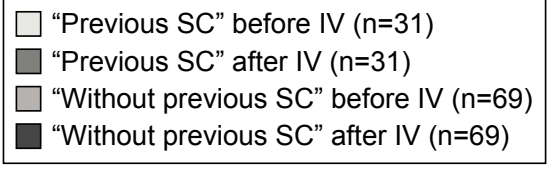

Figure I Actual question: How satisfied are you with using an IV infusion medication? Patient satisfaction with IV infusion therapy (A) and favorability of IV treatment before and after initiating IV infusion therapy for all patients (B) and for patients with and without previous experience with SC agents (C).

Abbreviations: IV, intravenous; SC, subcutaneous.

Among all patients, 33\% had an "extremely favorable" perception of IV therapy before initiating their current IV treatment, and this increased to $71 \%$ following initiation of their current therapy $(P<0.0001)$ (Figure 1B). Likewise, the mean \pm SD favorability perception score for IV therapy increased from $3.73 \pm 1.21$ to $4.54 \pm 0.87$ after patients initiated their current IV infusion therapy. The increase in favorability among patients' perception of their current IV therapy was

Table I Patient agreement with statements regarding use of current IV biologic therapy for IA (5-point scale: I= strongly disagree, $5=$ strongly agree)

\begin{tabular}{|c|c|c|c|}
\hline & $\begin{array}{l}\text { All patients } \\
(n=100)\end{array}$ & $\begin{array}{l}\text { No previous } \\
\text { self-injection } \\
(n=69)\end{array}$ & $\begin{array}{l}\text { Previous } \\
\text { self-injection } \\
(n=3 I)\end{array}$ \\
\hline My doctor felt strongly that an IV medication was the best choice for me & $4.55 \pm 0.67$ & $4.5 \mathrm{I} \pm 0.72$ & $4.65 \pm 0.55$ \\
\hline The doctor can adjust the dose of medication if needed & $4.49 \pm 0.82$ & $4.5 \mathrm{I} \pm 0.78$ & $4.45 \pm 0.93$ \\
\hline I believe that IV medications are strong medications & $4.24 \pm 0.78$ & $4.25 \pm 0.85$ & $4.23 \pm 0.62$ \\
\hline $\begin{array}{l}\text { For my lifestyle, it is easier for me to schedule an appointment at an } \\
\text { infusion center than to remember when to give myself shots }\end{array}$ & $4.17 \pm 1.10$ & $4.48 \pm 0.87$ & $3.48 \pm 1.26$ \\
\hline I believe an IV infusion would not be painful & $4.12 \pm 0.82$ & $4.28 \pm 0.71$ & $3.77 \pm 0.96$ \\
\hline Other medications did not control my symptoms & $4.06 \pm 0.91$ & $4.09 \pm 0.92$ & $4.00 \pm 0.89$ \\
\hline The infusion center is close to my home or office, making it convenient & $3.89 \pm 1.25$ & $3.94 \pm 1.25$ & $3.77 \pm 1.26$ \\
\hline $\begin{array}{l}\text { I would be concerned about the risk of hurting or injuring myself if I had } \\
\text { to give myself shots }\end{array}$ & $3.76 \pm 1.32$ & $4.20 \pm 1.10$ & $2.77 \pm 1.26$ \\
\hline I don't like needles and don't like the idea of having to give myself shots & $3.72 \pm 1.32$ & $3.99 \pm 1.28$ & $3.13 \pm 1.23$ \\
\hline $\begin{array}{l}\text { My co-pay or out-of-pocket cost is lower with an IV infusion medication } \\
\text { than medications that I would have to administer as shots }\end{array}$ & $3.53 \pm 1.00$ & $3.65 \pm 0.94$ & $3.26 \pm 1.09$ \\
\hline
\end{tabular}

Note: Data presented as mean \pm SD.

Abbreviations: IA, inflammatory arthritis; IV, intravenous. 
independent of whether they had previously received an SC biologic for IA (Figure 1C).

Patients with prior SC biologic experience $(n=31)$ were presented with possible reasons for why they switched from an SC to an IV biologic. The distribution of level of agreement with these choices is shown in Figure 2. These patients agreed most strongly with the statement, "The medication administered by shots wasn't working" (mean score \pm SD: $4.03 \pm 1.08$ ). Mean responses to the other reasons presented to patients were generally "Neutral" (neutral $=3$,
A

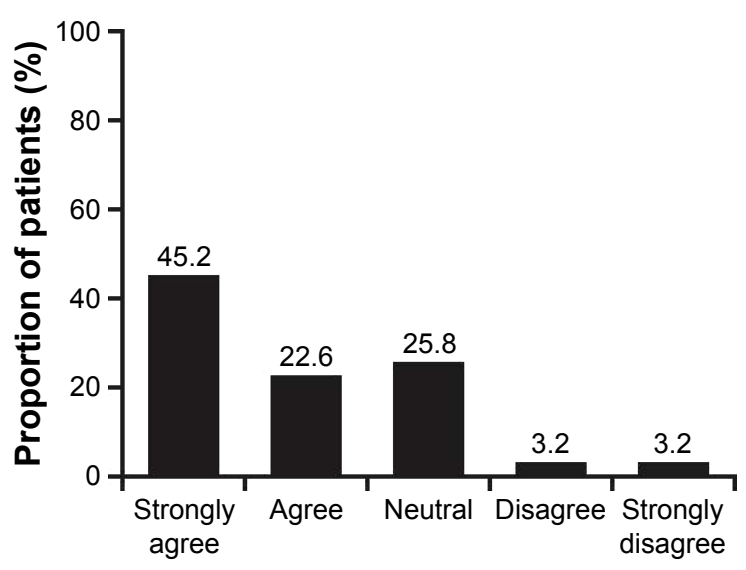

C

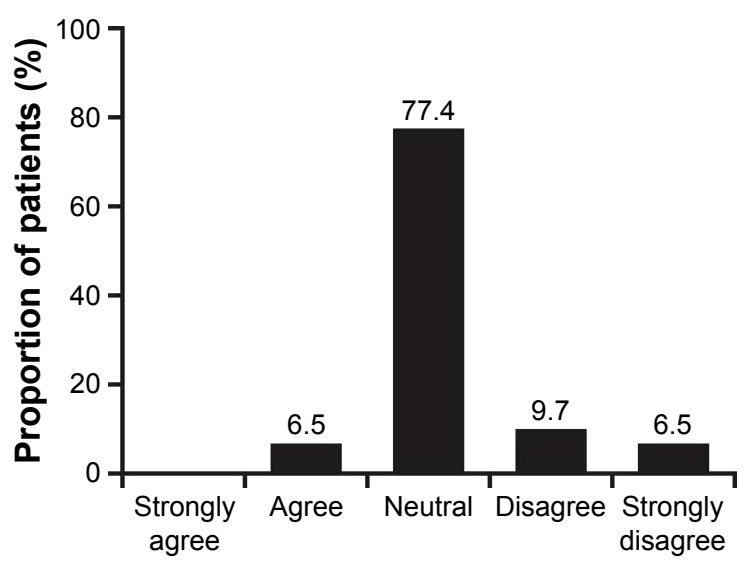

E

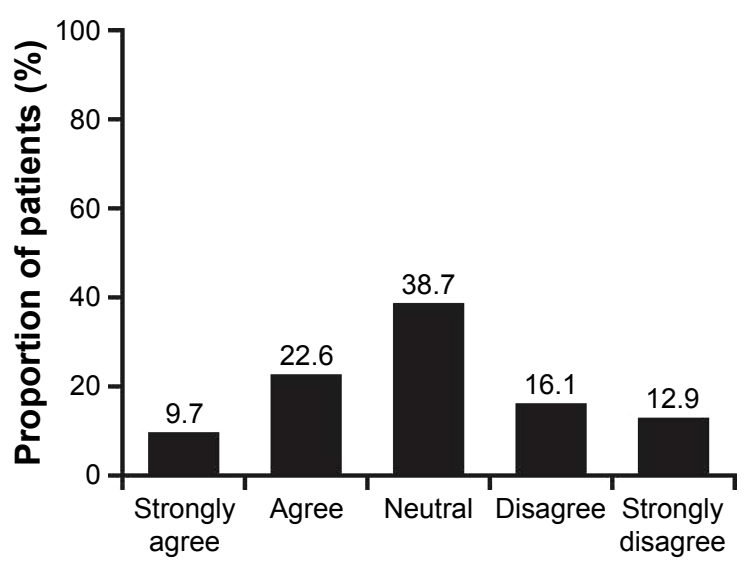

B
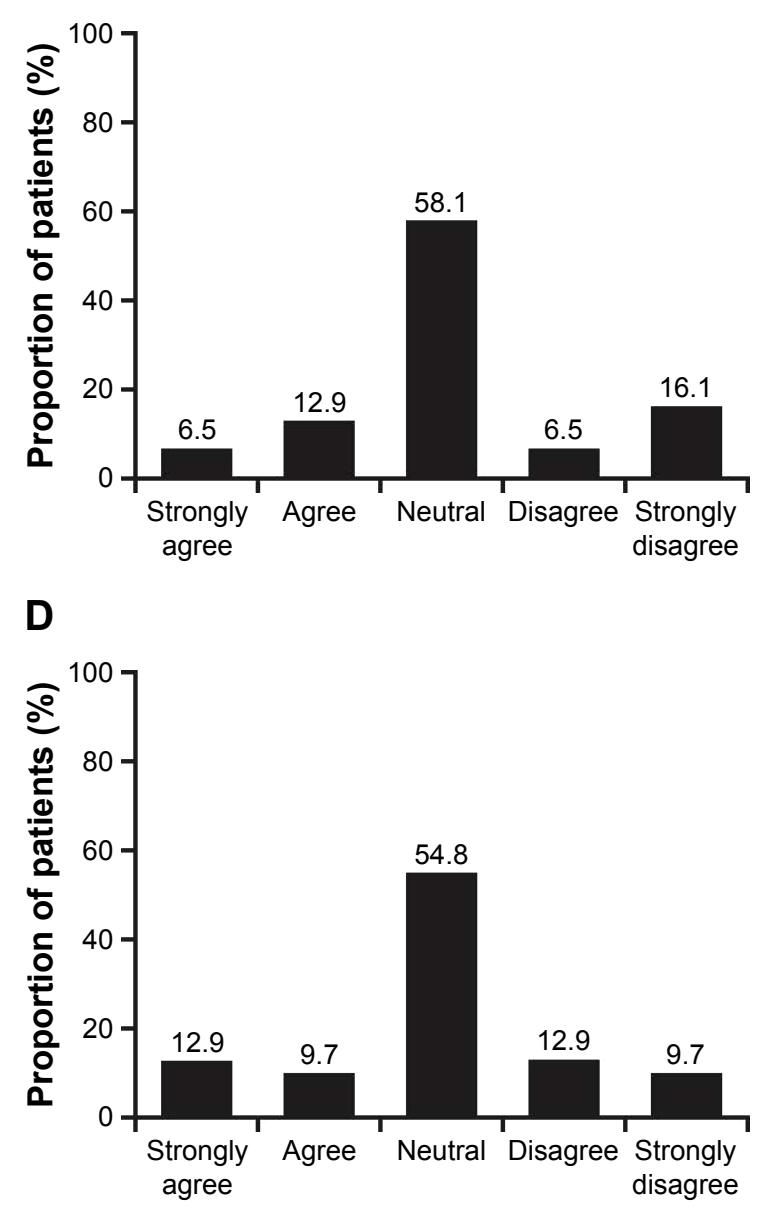

$\mathbf{F}$

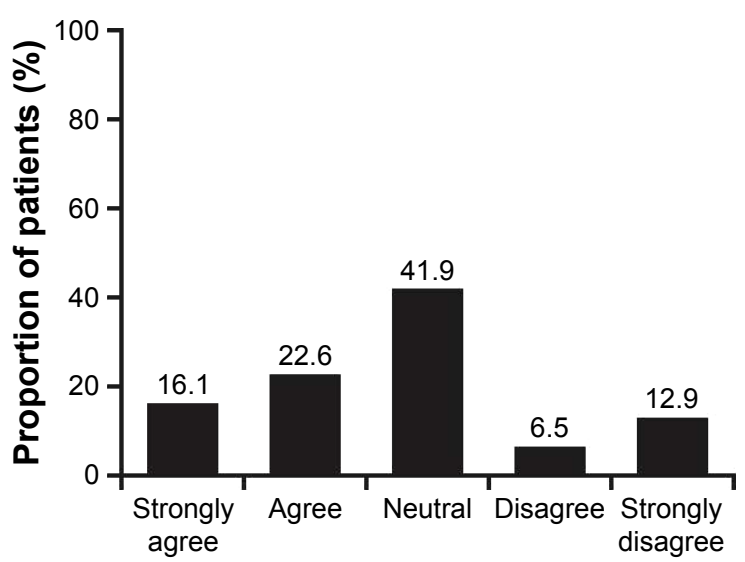

Figure $\mathbf{2}$ Level of patient agreement with reasons for switching from SC to IV therapy for IA: (A) The medication administered by shots wasn't working. (B) I had side effects to the medication administered by shots. (C) The cost of IV infusion medication was less. (D) I had difficulty remembering when to administer the shots. (E) I had difficulty administering the shots. (F) I didn't like giving myself shots.

Abbreviations: IA, inflammatory arthritis; IV, intravenous; SC, subcutaneous. 
patients tending to not agree or disagree): side effects from SC medication (2.87), cost of IV medication (2.84), difficulty remembering when to administer SC medication (3.03), difficulty administering SC medication (3.00), and not liking to give $\mathrm{SC}$ injections to themselves (3.23).

Patients were presented with several possible advantages and disadvantages of using IV biologics and asked to rate how strongly they agreed $(1=$ strongly disagree, $5=$ strongly agree) with the statements (Table 2). Of the possible advantages, patients agreed most strongly with the statement "The medication is being administered by professionals who can monitor for any side effects" (mean \pm SD score: 4.79 \pm 0.50 ). Patient responses were neutral toward the potential advantages "Infusion therapy is less costly" (3.42 \pm 1.12$)$ and "I take advantage of other activities such as shopping or going out to eat on days when I have to go to the infusion center"
(3.32 \pm 1.18$)$. Mean scores for the potential disadvantages that were presented to patients (eg, I have to travel to an infusion facility center [2.79 \pm 1.31$]$ and the duration of the infusion itself takes too much time [2.47 \pm 1.15$]$ ) were all below 3 (neutral). This indicates that from the perspective of the patients, they did not strongly agree that the proposed statements were in fact disadvantages. No outstanding disadvantage to using IV biologics was identified by these patients. There were no apparent differences in the responses to either potential advantages or disadvantages between patients who had previously used SC biologics and those who had not (Figure 2).

All patients were asked to rate their level of agreement with potential advantages and disadvantages of receiving their IA medication by an SC injection (Table 3). All of the statements describing the potential benefits of SC treatment

Table 2 Patient agreement with potential advantages and disadvantages to receiving IV infusion therapy for IA (5-point scale: I=strongly disagree, $5=$ strongly agree)

\begin{tabular}{|c|c|c|c|}
\hline & $\begin{array}{l}\text { All patients } \\
(n=100)\end{array}$ & $\begin{array}{l}\text { No previous } \\
\text { self-injection } \\
(n=69)\end{array}$ & $\begin{array}{l}\text { Previous } \\
\text { self-injection } \\
(n=3 I)\end{array}$ \\
\hline \multicolumn{4}{|l|}{ Potential advantages } \\
\hline $\begin{array}{l}\text { The medication is being administered by professionals who can monitor for } \\
\text { any side effects }\end{array}$ & $4.79 \pm 0.50$ & $4.77 \pm 0.52$ & $4.84 \pm 0.45$ \\
\hline $\begin{array}{l}\text { The staff at the infusion center keeps track of when I need my next dose of } \\
\text { medication and my next doctor's appointment and keeps me on schedule }\end{array}$ & $4.69 \pm 0.61$ & $4.67 \pm 0.68$ & $4.74 \pm 0.44$ \\
\hline The staff of medical professionals can assess how I am doing & $4.68 \pm 0.57$ & $4.67 \pm 0.59$ & $4.7 \mathrm{I} \pm 0.53$ \\
\hline $\begin{array}{l}\text { The visit for my infusion provides another assessment beyond my regular } \\
\text { doctor visit }\end{array}$ & $4.45 \pm 0.70$ & $4.36 \pm 0.75$ & $4.65 \pm 0.55$ \\
\hline I want to have a health-care professional administer the medication to me & $4.44 \pm 0.81$ & $4.55 \pm 0.74$ & $4.19 \pm 0.91$ \\
\hline Infusion therapy is more consistent with my lifestyle & $4.21 \pm 0.99$ & $4.39 \pm 0.84$ & $3.8 \mathrm{I} \pm 1.17$ \\
\hline With IV therapy, I don't have to fear about injecting myself & $4.20 \pm 1.03$ & $4.48 \pm 0.87$ & $3.58 \pm 1.12$ \\
\hline I like being able to socialize with the staff and other patients at the infusion unit & $4.15 \pm 0.90$ & $4.22 \pm 0.91$ & $4.00 \pm 0.89$ \\
\hline $\begin{array}{l}\text { The staff of medical professionals at the infusion center can also monitor my } \\
\text { other medical conditions }\end{array}$ & $4.13 \pm 0.96$ & $4.16 \pm 0.93$ & $4.06 \pm 1.03$ \\
\hline The infrequent dosing is an advantage & $4.09 \pm 0.90$ & $4.22 \pm 0.81$ & $3.80 \pm 1.03$ \\
\hline Infusion therapy is less costly & $3.42 \pm 1.12$ & $3.58 \pm 1.12$ & $3.06 \pm 1.06$ \\
\hline $\begin{array}{l}\text { I take advantage of other activities such as shopping or going out to eat on } \\
\text { days when I have to go to the infusion center }\end{array}$ & $3.32 \pm 1.18$ & $3.39 \pm 1.24$ & $3.16 \pm 1.04$ \\
\hline \multicolumn{4}{|l|}{ Potential disadvantages } \\
\hline I have to travel to an infusion facility & $2.79 \pm 1.31$ & $2.74 \pm 1.29$ & $2.90 \pm 1.37$ \\
\hline The cost of the infusion, such as the co-insurance or co-pay costs & $2.55 \pm 1.22$ & $2.57 \pm 1.23$ & $2.52 \pm 1.21$ \\
\hline The infusion itself takes too much time & $2.47 \pm 1.15$ & $2.46 \pm 1.17$ & $2.48 \pm 1.12$ \\
\hline Frequent scheduling issues, such as time off work, finding a babysitter, etc & $2.30 \pm 1.16$ & $2.33 \pm 1.18$ & $2.23 \pm 1.12$ \\
\hline The cost of going to the infusion center, such as gas, parking, etc & $2.26 \pm 1.14$ & $2.22 \pm 1.15$ & $2.35 \pm 1.14$ \\
\hline Missing several hours from work or school & $2.23 \pm 1.12$ & $2.32 \pm 1.13$ & $2.03 \pm 1.08$ \\
\hline I don't like seeing the IV needle & $2.22 \pm 1.12$ & $2.26 \pm 1.17$ & $2.13 \pm 0.99$ \\
\hline The loss of vacation days from work & $2.15 \pm 1.09$ & $2.23 \pm 1.11$ & $1.97 \pm 1.02$ \\
\hline The need for IV treatment reminds me that I am sick & $2.15 \pm 1.15$ & $2.13 \pm 1.16$ & $2.19 \pm 1.14$ \\
\hline I don't like being in a setting with other people who may be very ill & $1.97 \pm 0.95$ & $1.97 \pm 1.00$ & $1.97 \pm 0.84$ \\
\hline The IV infusion is difficult since I have poor veins & $1.92 \pm 1.08$ & $1.94 \pm 1.11$ & $1.87 \pm 1.02$ \\
\hline
\end{tabular}

Note: Data presented as mean \pm SD.

Abbreviations: IA, inflammatory arthritis; IV, intravenous. 
Table 3 Patient agreement with potential advantages and disadvantages of self-administration of SC therapy for IA (5-point scale: $\mathrm{I}=$ strongly disagree, $5=$ strongly agree)

\begin{tabular}{|c|c|c|c|}
\hline & $\begin{array}{l}\text { All patients } \\
(n=100)\end{array}$ & $\begin{array}{l}\text { No previous } \\
\text { self-injection } \\
(n=69)\end{array}$ & $\begin{array}{l}\text { Previous } \\
\text { self-injection } \\
(n=31)\end{array}$ \\
\hline \multicolumn{4}{|l|}{ Potential advantages } \\
\hline I could avoid a trip to the doctor's office & $2.68 \pm 1.25$ & $2.67 \pm 1.30$ & $2.7 I \pm I .16$ \\
\hline I would use less health-care resources & $2.63 \pm 0.99$ & $2.62 \pm 0.99$ & $2.65 \pm 1.02$ \\
\hline Injections (shots) are less costly for me & $2.60 \pm 0.95$ & $2.56 \pm 0.98$ & $2.68 \pm 0.87$ \\
\hline I have more control of when I take my medicine & $2.36 \pm 1.14$ & $2.32 \pm 1.19$ & $2.45 \pm 1.03$ \\
\hline I am comfortable giving myself shots & $2.33 \pm 1.33$ & $2.14 \pm 1.36$ & $2.74 \pm 1.18$ \\
\hline I feel I am in more control of my disease & $2.26 \pm 1.19$ & $2.17 \pm 1.24$ & $2.45 \pm 1.09$ \\
\hline I can remember to give myself shots vs remembering an appointment & $2.25 \pm 1.13$ & $2.13 \pm 1.17$ & $2.52 \pm 1.00$ \\
\hline I don't want to be around others when getting a medical treatment & $2.03 \pm 0.95$ & $1.99 \pm 0.98$ & $2.13 \pm 0.88$ \\
\hline \multicolumn{4}{|l|}{ Potential disadvantages } \\
\hline $\begin{array}{l}\text { There is no medical staff immediately available if I experience side effects } \\
\text { from the medication }\end{array}$ & $4.08 \pm 1.10$ & $4.10 \pm 1.18$ & $4.03 \pm 0.91$ \\
\hline $\begin{array}{l}\text { I would worry about the refrigeration, keeping refrigerated while traveling, } \\
\text { ordering the medication from the pharmacy, etc }\end{array}$ & $3.89 \pm 1.19$ & $3.91 \pm 1.27$ & $3.84 \pm 1.00$ \\
\hline I am not comfortable injecting myself & $3.88 \pm 1.16$ & $4.09 \pm 1.15$ & $3.42 \pm 1.06$ \\
\hline The doctor may not be able to adjust the dose of medication with the shot & $3.85 \pm 1.07$ & $3.87 \pm 1.16$ & $3.8 I \pm 0.87$ \\
\hline I would worry about disposing of the needles & $3.7 I \pm I .23$ & $3.80 \pm 1.26$ & $3.52 \pm 1.15$ \\
\hline I need to remember when to give myself shots & $3.70 \pm 1.21$ & $3.59 \pm 1.33$ & $3.94 \pm 0.85$ \\
\hline $\begin{array}{l}\text { I would worry about having needles in the house (potential danger to } \\
\text { children and pets) }\end{array}$ & $3.55 \pm 1.26$ & $3.67 \pm 1.29$ & $3.29 \pm 1.16$ \\
\hline $\begin{array}{l}\text { There is no opportunity for socialization, such as talking with the staff or } \\
\text { other patients with my condition }\end{array}$ & $3.50 \pm 1.17$ & $3.55 \pm 1.23$ & $3.39 \pm 1.02$ \\
\hline My out-of-pocket costs might be higher (co-pay, co-insurance) & $3.27 \pm 1.01$ & $3.32 \pm 1.03$ & $3.16 \pm 0.97$ \\
\hline I have too many other medical conditions to take care of already & $3.29 \pm 1.18$ & $3.30 \pm 1.28$ & $3.26 \pm 0.96$ \\
\hline
\end{tabular}

Note: Data presented as mean \pm SD.

Abbreviations: IA, inflammatory arthritis; SC, subcutaneous.

received mean scores $<3$ (neutral). The opposite was observed for statements regarding potential disadvantages of receiving their medication as an $\mathrm{SC}$ injection, with mean scores $>3$. Patients agreed most strongly with the potential disadvantage statement of "There is no medical staff immediately available if I experience side effects from the medication" (mean \pm SD disadvantage score: 4.08 \pm 1.10 ). Mean patient responses to the potential disadvantages and advantages of receiving treatment as an SC injection were similar whether the patients had previous experience with self-injection (Table 3).

Thirty-nine patients reported that they had to take time off from work to receive their IV infusion. The majority of these patients agreed or strongly agreed that it was not a problem to miss time from work to receive their infusion; few patients agreed with statements indicating difficulties with missing time from work to receive their infusions (Table 4). Sixty-one percent of all patients reported that travel time to

Table 4 Patient agreement with statements regarding difficulty missing time from work, among those who miss time from work to receive infusions for IA $(n=39)$

\begin{tabular}{|c|c|c|c|c|c|}
\hline & $\begin{array}{l}\text { Strongly } \\
\text { agree }\end{array}$ & Agree & Neutral & Disagree & $\begin{array}{l}\text { Strongly } \\
\text { disagree }\end{array}$ \\
\hline \multicolumn{6}{|l|}{ How difficult is it to get the time off from work, $n$ (\%) } \\
\hline Not a problem - the company (or supervisor) is very understanding & $21(53.8)$ & $13(33.3)$ & $5(12.8)$ & - & - \\
\hline Not a problem - I make up the time later in the week & $15(38.5)$ & $7(17.9)$ & II (28.2) & $3(7.7)$ & $3(7.7)$ \\
\hline $\begin{array}{l}\text { Slight problem - I always have to negotiate when I can leave and when } \\
\text { the time will be made up }\end{array}$ & $2(5.1)$ & $2(5.1)$ & $10(25.6)$ & $10(25.6)$ & $15(38.5)$ \\
\hline It's a problem - I need to sneak out early or call in sick to make the visit & $\mathrm{I}(2.6)$ & $\mathrm{I}(2.6)$ & $10(25.6)$ & $9(23.1)$ & $18(46.2)$ \\
\hline It's a problem since I don't get paid for the time I miss at work & $2(5.1)$ & $4(10.3)$ & $8(20.5)$ & $9(23.1)$ & $16(4 \mid .0)$ \\
\hline
\end{tabular}

Note: Data presented as n (\%).

Abbreviation: IA, inflammatory arthritis. 
the infusion center was $<30$ minutes, while $36 \%$ reported travel time between 31 and 60 minutes, and $3 \%$ of patients reported that their travel time was $>60$ minutes. Mean agreement scores ( $1=$ strongly disagree, $5=$ strongly agree $)$ for the statements "Not a problem; my company or supervisor is understanding" and "Not a problem; I make up the time later in the week" were $4.41 \pm 0.72$ and $3.72 \pm 1.28$, respectively, indicating agreement; whereas, mean agreement scores for the statements "It's a problem; I need to sneak out early or call in sick to make the visit" and "It's a problem; I don't get paid for the time I miss at work" were 1.92 \pm 1.04 and $2.15 \pm 1.23$, respectively, indicating less agreement by the patients with these statements.

\section{Discussion}

There are a variety of factors that influence a patient's decision in regards to choosing therapy for their IA. Among the available choices are biologic drugs administered either as an SC injection or IV infusion. A key component in the decision-making process is the patient-physician relationship. It is increasingly evident that the physician should discuss the advantages and disadvantages of each treatment option with the patient. ${ }^{5-7}$ As the results of this study indicate, some patients may perceive meaningful differences between treatment modalities. Other patients may identify advantages with a certain route of administration based on individual preferences and perceptions. The results presented here support a shared decision-making process between the patient and the physician, in which the patient is offered the available options in sufficient detail, and then the patient's perception and preference for treatment options are highly considered.

In this study of 100 patients currently receiving IV therapy for IA, there was a high level of satisfaction among all patients with regard to their experience with IVadministered biologic therapy. A total of $90 \%$ of patients ranked their satisfaction with IV therapy as 4 or 5 , with $77 \%$ ranking satisfaction as 5 (very satisfied). These results align with a recent publication in which $82 \%$ of patients receiving an IV biologic to treat an autoimmune disease (ie, ankylosing spondylitis, rheumatoid arthritis, psoriatic arthritis, psoriasis, Crohn's disease, or ulcerative colitis) indicated a preference for an IV-administered treatment over an SC-administered treatment. ${ }^{8}$ In our study, overall, the decision to use IV therapy was influenced primarily by the patients' perception of efficacy and the opinion of their treating physician. Patients also tended to strongly agree with the statement that it was easier to schedule appointments for their infusions rather than remember to self-administer SC injections. Among patients who switched from an SC therapy to an IV therapy, the primary reason for switching (among those in the questionnaire presented to the patient) pertained to efficacy. A total of $67.8 \%$ of patients either agreed or strongly agreed that the switch to IV infusion was related to the SC medication "not working". The reason for switching with the next highest level of agreement (agreed or strongly agreed) was that patients did not like giving themselves SC injections (38.7\%). Among other possible reasons, the majority of patients were neutral, disagreed, or strongly disagreed regarding adverse events (80.7\%), lower cost of IV medication (93.6\%), difficulty remembering when to administer SC injections (77.4\%), or difficulty administering the SC injection (67.7\%) as the rationale for switching from SC to IV.

There was no apparent difference in the degree of favorability reported for receiving IV therapy between the patients who had previously used SC biologic therapy and those who had not received prior SC therapy. Overall, patients who had previously received SC therapy and later switched to IV therapy identified multiple benefits of infusion therapy which were not available to them while they were self-injecting. Although the differences were not statistically significant, it is interesting to note that the four "advantage" statements with the highest agreement scores overall (among all patients) had even higher agreement scores among patients with prior SC injection experience. Overall, these highest-ranking potential advantages of IV treatment suggest that constant professional reinforcement of disease management, readily available health-care resources to assist with any problem, and relationships developed with the staff are meaningful to patients receiving IV biologic treatment. These factors should be discussed as part of the shared decision-making process.

Patients in our study had a more favorable perception of IV therapy after receiving this therapy compared with their recollection of how they felt about it before receiving IV therapy. This relative shift in perception was observed for both patients who had, and those who had not, received SC biologic therapy previously. Regarding their use of IV medication, reasons with the greatest agreement score pertained to physician input on what the best therapy was for the patients and that the physician would be able to adjust the dose of medication as needed. These reasons were the highest ranking independent of prior SC injection experience. Similarly, among the potential advantages of IV therapy, the highest-ranking factor pertained to the level of health care provided as a component of the IV infusion experience. Again, highest-ranking potential advantages 
were independent of prior SC injection experience. These results suggest that patients had improved control of their disease after receiving IV therapy and may have developed a relationship with the infusion provider. Likewise, patients may have bonded with the nurses, medical assistants, and/or physicians at the site where this study was conducted. It was observed that the average time patients had received their IV therapy was $>4$ years, supporting the potential of a relationship-building aspect. Finding the time to have a monthly, bi-monthly, or every-6-month infusion did not appear to be a problem for the majority of patients. The need to schedule the time off, either professionally or personally, seemed to be an acceptable part of the infusion treatment plan. In some instances, patients reported a level of positivity toward being able to take a break from a schedule of normal life activities to come in for an infusion where all of the work was done by the staff and the experience was favorable. Of note, nearly all patients reported having been educated about their IV infusion before starting treatment. Most of these patients (97\%) reported receiving consultation from a physician; $37 \%$ also spoke with a nurse or a nurse practitioner. A survey of Belgian patients with rheumatoid arthritis and rheumatologists (the Be-Raise study) demonstrated that patients' primary concerns were centered on effectiveness of treatment. ${ }^{9}$ There was a notable difference in the patient-reported satisfaction with IV therapy (52.4\%) and the perceived patient satisfaction reported by physicians $(29.9 \%){ }^{9}$ These results also support a shared decision-making conversation with effective discussions between health care professionals and patients before initiating therapy being a critical component of the shared decision-making process regarding drug therapy choices.

The relative importance of patient perspective in treatment preferences of IA has also been assessed in a younger population. In a study of patients aged 16-25 years who were diagnosed with a spectrum of IA diseases, it was determined that leading a "normal" life was an important overall goal from the patients' perspective. ${ }^{10}$ Hart et al also found that young patients need active encouragement to discuss their treatment concerns and difficulties with the care team, ${ }^{10} \mathrm{a}$ conclusion that coincides with our findings that support a shared decision-making approach.

This study was conducted at a single site, which may limit the generalizability of the results. For example, only $38 \%$ of the population was reported as Caucasian and $28 \%$ were reported as African American. This distribution is different from a broader US-based IA population. ${ }^{11}$ Furthermore, some of the items in the questionnaire relied on the patients' recall of their prior perceptions and experiences. Patients also tended to have positive perceptions of their current health status with IV therapy (majority rating of 4 or 5 , with 5 being perfect health), possibly suggesting an overall positive attitude toward IV infusion therapy. Despite these limitations, our results demonstrate the characteristics and perceptions of patients with IA receiving ongoing IV therapy.

Overall, the 100 patients who had received infusion therapy for $\geq 3$ months for their IA had a positive perception regarding IV therapy. Of note, patients previously treated with SC therapy had a similar positive perception. This would suggest that physicians should strongly consider that patients may be open and amenable to an infusion therapy option as part of a shared decision discussion. Furthermore, this illustrates the value of an outpatient infusion center where there are experts, a consistent and knowledgeable staff, and a comfortable environment which may be desirable and beneficial to patients.

\section{Acknowledgments}

The authors thank Daniel Tuccitto, an independent contractor for Arthritis \& Rheumatic Disease Specialties, and Yanli Wang, MS, of Janssen Research \& Development, LLC, for providing statistical support and Rebecca E Clemente, PhD, of Janssen Scientific Affairs, LLC, for editorial support. This study was sponsored by Janssen Scientific Affairs, LLC, Horsham, PA, USA.

\section{Disclosures}

NBG has received speaking fees from Janssen. WAK was an employee of Janssen Scientific Affairs, LLC, at the time this work was performed. SB, RD, and DP are employees of Janssen Scientific Affairs, LLC, and own stock in Johnson \& Johnson, of which Janssen Scientific Affairs, LLC, is a wholly owned subsidiary. KLT was an employee of Janssen Research \& Development, LLC, at the time this work was performed and owns stock in Johnson \& Johnson, of which Janssen Research \& Development, LLC, is a wholly owned subsidiary. The authors report no other conflicts of interest in this work.

\section{References}

1. Charles C, Gafni A, Whelan T. Decision-making in the physician-patient encounter: revisiting the shared treatment decision-making model. Soc Sci Med. 1999;49(5):651-661.

2. Sylwestrzak G, Liu J, Stephenson JJ, Ruggieri AP, DeVries A. Considering patient preferences when selecting anti-tumor necrosis factor therapeutic options. Am Health Drug Benefits. 2014;7(2):71-81.

3. Scarpato S, Antivalle M, Favalli EG, et al. Patient preferences in the choice of anti-TNF therapies in rheumatoid arthritis. Results from a questionnaire survey (RIVIERA study). Rheumatology (Oxford). 2010;49(2): 289-294. 
4. Nota I, Drossaert CH, Taal E, Vonkeman HE, van de Laar MA. Patient participation in decisions about disease modifying anti-rheumatic drugs: a cross-sectional survey. BMC Musculoskelet Disord. 2014;15:333.

5. Salt E, Peden A. The complexity of the treatment: the decision-making process among women with rheumatoid arthritis. Qual Health Res. 2011;21(2):214-222.

6. Curtis JR, Shan Y, Harrold L, Zhang J, Greenberg JD, Reed GW. Patient perspectives on achieving treat-to-target goals: a critical examination of patient-reported outcomes. Arthritis Care Res (Hoboken). 2013;65(10): 1707-1712.

7. Martin RW, Head AJ, Rene J, et al. Patient decision-making related to antirheumatic drugs in rheumatoid arthritis: the importance of patient trust of physician. J Rheumatol. 2008;35(4):618-624.

8. Bolge SC, Eldridge HM, Lofland JH, Ravin C, Hart PJ, Ingham MP. Patient experience with intravenous biologic therapies for ankylosing spondylitis, Crohn's disease, psoriatic arthritis, psoriasis, rheumatoid arthritis, and ulcerative colitis. Patient Prefer Adher. 2017;11: 661-669.
9. De Mits S, Lenaerts J, Vander Cruyssen B, et al. A nationwide survey on patient's versus physician's evaluation of biological therapy in rheumatoid arthritis in relation to disease activity and route of administration: The Be-Raise study. PLoS One. 2016;11(11):e0166607.

10. Hart RI, McDonagh JE, Thompson B, et al. Being as normal as possible: how young people ages 16-25 years evaluate the risks and benefits of treatment for inflammatory arthritis. Arthritis Care Res (Hoboken). 2016; 68(9):1288-1294

11. Helmick CG, Felson DT, Lawrence RC, et al. Estimates of the prevalence of arthritis and other rheumatic conditions in the United States. Part I. Arthritis Rheum. 2008;58(1):15-25. 


\section{Supplementary material}

Table SI Baseline demographic and disease characteristics

\begin{tabular}{|c|c|c|c|}
\hline Demographics & Patients $(n=100)$ & Disease characteristics & Patients $(n=100)$ \\
\hline Age, years & $58.35 \pm 14.64$ & Disease duration, years & $10.10 \pm 8.14$ \\
\hline Female & 66 & Disease duration range, years & $0.67-45.00$ \\
\hline Weight, kg & $85.03 \pm 19.69$ & Disease diagnosis & \\
\hline $\mathrm{BMI}, \mathrm{kg} / \mathrm{m}^{2}$ & $30.29 \pm 5.98$ & Rheumatoid arthritis & 68 \\
\hline Race & & Ankylosing spondylitis & 9 \\
\hline Caucasian & 38 & Psoriatic arthritis & 21 \\
\hline African American & 28 & Crohn's disease/IA & 2 \\
\hline Latino/Hispanic & 22 & Medical history & \\
\hline Asian/Pacific Islander & I & Heart disease & 7 \\
\hline Not identified & 11 & Congestive heart failure & I \\
\hline Education & & Hypertension & 44 \\
\hline Grade school & 3 & Insulin-dependent diabetes & 4 \\
\hline Some high school & 3 & Non-insulin-dependent diabetes & 11 \\
\hline High school graduate & 19 & Stroke & 2 \\
\hline Some college & 24 & Peripheral vascular disease & 5 \\
\hline College graduate & 29 & Skin cancer & 8 \\
\hline Graduate school & 17 & Cancer & 5 \\
\hline Trade school & 5 & Hepatitis & 3 \\
\hline Employment status & & Tuberculosis & 0 \\
\hline Full-time job & 48 & Chronic infection & 3 \\
\hline Part-time job & 7 & Stomach/Duodenal ulcer & 9 \\
\hline Student & I & COPD/Emphysema & 5 \\
\hline Homemaker & I & Current health score ${ }^{\mathrm{a}}$ & \\
\hline Retired/unemployed & 43 & 1 & 2 \\
\hline Health insurance & & 2 & 5 \\
\hline Medicare & 39 & 3 & 24 \\
\hline Medicaid & 7 & 4 & 43 \\
\hline Private & 72 & 5 & 26 \\
\hline
\end{tabular}

Notes: Data presented as $\mathrm{n}$ or mean \pm SD. aPatients were asked: "On a scale of $\mathrm{I}-5$, how would you rate your health over the past month?" $\mathrm{I}=\mathrm{Very}$ poor health, $5=$ Perfect health.

Abbreviations: BMI, body mass index; COPD, Chronic Obstructive Pulmonary Disease; IA, inflammatory arthritis.

\section{Publish your work in this journal}

Patient Preference and Adherence is an international, peer-reviewed, open access journal that focuses on the growing importance of patient preference and adherence throughout the therapeutic continuum. Patient satisfaction, acceptability, quality of life, compliance, persistence and their role in developing new therapeutic modalities and compounds to optimize clinical outcomes for existing disease states are major areas of interest for the journal. This journal has been accepted for indexing on PubMed Central. The manuscript management system is completely online and includes a very quick and fair peer-review system, which is all easy to use. Visit http://www. dovepress.com/testimonials.php to read real quotes from published authors.

Submit your manuscript here: http://www.dovepress.com/patient-preference-and-adherence-journal 